\title{
Innovations in community physiotherapy
}

\author{
M. Ellangovin \\ MPT Senior Consultant, Gonoshasthaya Kendra and Head \& Associate Professor, \\ Gono Bishwabidyalay, Bangladesh
}

\begin{abstract}
.
\section{Background}

In the last 35 years, Bangladesh has produced only 415 physiotherapists to meet the demands of a total population of 150 million. Most of them practice in the capital city of Dhaka because of better business prospects. The need to formulate an innovative strategy to meet the huge demand is obvious.

According to a World Bank report (2005), 44\% (poor) and 33\% (very poor) people approach local pharmacists or medicine sellers for their ailments due to poor accessibility to healthcare facilities and also to avoid consultation fees.
\end{abstract}

\section{Methods}

Due to scarcity in the number of professionals, community physiotherapists have become popular with rural patients. They use innovative treatment approaches, which combines traditional Physiotherapy and ancient Ayurvedic massage. Targeting equitable access to all, Gonoshasthaya Kendra (GK) has its own health insurance policy. The fee is determined by the socio-economic status of the patient.

\section{Results}

Experienced paramedics are now able to administer treatment without direct supervision all the time. The number of patients seen by them is multiplying at a fascinating rate every year due to the growing recognition of their work.

\section{Conclusion}

Gonoshasthaya Kendra (GK) was established in 1972 and provides primary health care to a rural population of over 1.08 million across 629 villages in Bangladesh. The strategies and methods adopted by Gonoshasthaya Kendra in bridging the gap and promoting community physiotherapy by training health workers or "paramedics" in Bangladesh, has been successful. Even though training of many more paramedics is required, success is guaranteed.

\section{Introduction}

Bangladesh has a population of 143.8 million, living in about 147570 square kilometers and growing at the rate of $1.48 \%$ per annum. About $70 \%$ of the population lives in the rural areas. Administratively, the country is divided into 6 divisions, 64 districts, 507 upazilas and 4533 unions, each one inhabited by a population of about 22 million, 2 million, 255 thousand and 29 thousand, respectively (https://www.cia.gov/library/publications/

\section{Correspondence to: $\mathrm{M}$. Ellangovin}

(mani_mpt@hotmail.com) the-world-factbook/geos/bg.html). Each union is divided into 9 wards.

In the last three decades, there has been remarkable improvement in the healthcare provided to the people of Bangladesh. The average life expectancy at birth in Bangladesh has increased to over 65 years (National Health Policy (NHP), 2008). While progress in modern medicine has led to the prevention of many diseases and the mortality rate of aged and disabled people has dropped significantly, such people are now in need of more advanced care and rehabilitation than in the past.

Published by Copernicus Publications on behalf of the Institut Veolia Environnement. 
In Bangladesh, many reputable physicians unfortunately have little regard for accountability; consultation time with patients is limited and often a diagnosis is made even before the patient has finished explaining his/her problem. Unfortunately when expected result do not follow with the speed of a doctor's prescription writing, patients tend to lose faith in their physicians and keep switching to different "experts" in search of someone better! Given this confusion, what role does a physiotherapist play? Unfortunately in the Bangladesh healthcare profession, they are regarded as intruders and are assumed to be ineffective in providing a proper treatment to patients. Due to this, physicians often refrain from referring patients to physiotherapists, even if therapy is the required treatment option.

The physiotherapy profession is s self-regulated health care profession. Physiotherapists work with their patients to plan and carry out individually designed physical treatment programs for the purpose of restoring function and preventing disability from disease, trauma or injury (Canadian Alliance of Physiotherapy Regulators \& the Canadian Physiotherapy Association, 2002). In Bangladesh, physiotherapy as a profession is not yet popular at the national level. There are no physiotherapists in government run hospitals or at any primary health care centers in Bangladesh! So physiotherapists in Bangladesh cater only to an elite clientele of patients who have some knowledge about the benefits of therapy.

In May 2002, the physiotherapy department of Gono Bishwabidyalay arranged camps at remote villages in Savar. When reviewing the medical history of a patient with neck pain, the patient produced an old prescription. The physician had prescribed Ibuprofen capsule (a pain killer), Ranitidine tablet (ulcer healing drug) and Physiotherapy for two weeks. Looking at the prescription, one intern inquired whether the patient was following the prescription properly. In reply, the patient answered promptly, "I went to all the local pharmacies in the area but none of them had the physiotherapy tablet. So I was able to take only two medicines instead of three. My neck pain did not go away". That made us realize how little rural people are aware of physiotherapy as a treatment option.

\section{Gonoshasthaya Kendra}

The 480-bedded makeshift hospital which was built during the Liberation War of Bangladesh in 1971 to serve the freedom fighters and refugees from Bangladesh, later emerged as Gonoshasthaya Kendra (GK) in the newly liberated Bangladesh in 1972 (Bose, 2004). GK's innovative work had earned a place in "The Lancet" editorial (3 January 1976, 1(7949), 26-7). Today GK is the largest health care providing organization, second to the Ministry of Health and Family Welfare in Bangladesh (The World Bank Office, Dhaka, 2007).
World Health Organization's "Health for All" programs' core activities started in GK from its very inception (Haque, 2003). The World Health Organization sited GK as an example in the declaration of the principles of "Health for All" in Alma Ata in 1978. Subsequently; GK extended and developed these programs by institutionalizing them. "Health for All" is accepted as principle and a vision by GK. All projects are interwoven with this basic aim. Concentrating on the poor, GK began by providing preventive and primary health care for the surrounding villages where access to health services was almost non-existent. GK provides Primary Health Care (PHC) to a rural population of over 1.08 million across 20 Upazila's, 629 villages (Gonoshasthaya Kendra, 2008). It has 13-project offices and 18 sub-centers to monitor the programs (Table 1).

In Bangladesh, "Paramedics" are well trained and a dedicated health workforce similar to health extension workers in Ethiopia and lady health workers and lady health visitors of Pakistan (WHO, 2006). In GK, paramedics perform the following routine tasks in villages such as community physiotherapy: examining pregnant women, post delivery followup, providing advice on child-care, information collection and report preparation, recording health insurance information, vaccination for disease protection, treatment of general diseases and referral, health education, and family planning, etc. The number of paramedics in the GK project offices ranges between $15-25$ and usually 12 in each sub-center.

The skills and expertise of the GK paramedics have been well appreciated by an esteemed medical journal "The Lancet" published in Britain and USA. On 27 September 1975 an article titled "Tubectomy by Paraprofessional Surgeons in Rural Bangladesh" was published in the aforesaid journal (Chowdhury and Chowdhury, 1975). In another comprehensive article published in a USA newspaper, "The Express", a front page story lauded the efforts of GK's paramedics, "Le-Plate Surgeon: cannot read or write but can operate" (http://www.express.co.uk).

\section{Methodology}

The objectives of community physiotherapy is to provide patients with quick-and-easy access to health service at their door step by training an army of health workers who are efficient, dedicated, non-tiring and always smiling. The underlying idea is to have adequate skilled paramedics at any given time to cater to patient needs in rural areas. In addition, a subsidized fee system for the underprivileged promotes demand for the service provided. Service innovations by GK such as paramedic training, combination therapy, promoting community physiotherapy rather than centre based health care, an insurance policy system and behavioral training etc. help to achieve the objectives of community physiotherapy. 
Table 1. GK's Project wise family chart.

\begin{tabular}{lcccccc}
\hline Sub centers & \multicolumn{5}{c}{ Population } \\
\cline { 2 - 6 } & Destitute & Ultra poor & Poor & Middle class & Rich & Total Population \\
\hline Pathlia & 17 & 40 & 17659 & 23234 & 2549 & 43499 \\
Dham sona & 27 & 74 & 17434 & 46655 & 3542 & 67732 \\
Zoron & 11 & 103 & 18651 & 28284 & 3536 & 50585 \\
Panishali & 18 & 177 & 21097 & 15948 & 2548 & 39788 \\
Shimulia & 152 & 951 & 29367 & 21430 & 2548 & 53751 \\
Barobaria & 24 & 113 & 23549 & 8704 & 1257 & 33751 \\
Saturia & 50 & 81 & 28037 & 17588 & 1941 & 47697 \\
Sreepur & 168 & 1264 & 69552 & 34657 & 7222 & 112863 \\
Vatshala & 183 & 1407 & 82878 & 17858 & 2272 & 104595 \\
Sonagazi & 89 & 206 & 26499 & 10417 & 1585 & 38796 \\
Shivgang & 18 & 321 & 54725 & 16883 & 5698 & 77645 \\
Char fashion & 120 & 4199 & 49257 & 7485 & 1644 & 62705 \\
Cox Bazaar & 513 & 2562 & 74700 & 19909 & 4389 & 102073 \\
Kashi nathpur & 110 & 586 & 47612 & 13539 & 3278 & 65125 \\
Sirajgang & 371 & 1849 & 74017 & 14355 & 2733 & 93325 \\
Parbatipur & 102 & 438 & 22060 & 5563 & 3167 & 31330 \\
Kanchipur & 218 & 3700 & 19047 & 4553 & 1027 & 28545 \\
Delduar & 1 & 112 & 18141 & 8869 & 952 & 28075 \\
\hline Total & 2192 & 18183 & 694282 & 315931 & 51191 & 1081779 \\
\hline
\end{tabular}

\subsection{Paramedic training}

To be eligible to train as a paramedic, the required entry qualification is at least a Secondary education certificate with at least a second division in science subjects. Almost 95\% of paramedics of GK are female. Paramedics are required to attend a 6 month basic training course, which is termed as a "foundation training" program. Following this, internship training for 18 months is mandatory; during these 18 months, trainees are assigned to visit 4000-5000 persons every month covering one or two villages. However, it is somewhat impossible to cover the targeted number by the end of each month and prepare reports at the same time. In all, a paramedic completes at least 6 years of training before obtaining a certificate.

The paramedics are selected from different sub-centers and brought to Savar, which acts as the main centre for the rural areas and basic training is conducted here. The certificate course in physiotherapy which runs for 6 weeks gives basic training on some of the common conditions and techniques to be applied in different specialties (Table 2).

Successful candidates are sent back to the sub-centers and during their field visits, if patients requiring physiotherapy are found, the paramedics then administer treatment. If they find it difficult to handle, the patients are referred to GK's two-referral hospitals, one is located in GK's head office premises at Savar and the other one is Gonoshasthaya Nagar Hospital at Dhaka. These two speciality hospitals have full time qualified physiotherapists who can take care of the pa- tient. It also has sufficient beds, doctors, intern-doctors, specialists, managers, supervisors, health workers/paramedics and other supporting staffs.

\subsection{Combination therapy}

In rural areas, without proper treatment, a patient faces a lot of stress and strain, which in turn leads to development of nodule-like structures in the muscles and they are the main reasons for pain and can handicap patients. So, until these nodules are dealt with effectively, pain management and rehabilitation is incomplete. Treatment for these patients with traditional physiotherapy techniques has not always yielded favourable results.

To tackle these secondary complications, physiotherapy (soft tissue mobilization \& hot pack) has been combined with ancient Ayurveda (massage with medicated oil). Ayurveda is an ancient system of medicine practiced at the home level and gives importance to natural medicines, massage and food habits. This form of therapy helps to identify the nodules and work on them to alleviate all secondary complications thereby making treatment more effective and giving permanent relief. This combined approach helps to resolve secondary complications faced by patients (Fig. 1).

Traditional physiotherapy departments are centre-based, dependent on equipment, electricity, lot of space etc. and is usually run by qualified therapists who prefer to practice in urban areas; in contrast, paramedics are more flexible with their choice of work locations and are available for 
Table 2. GK's Paramedic training in physiotherapy - course outline.

\begin{tabular}{|c|c|c|}
\hline Weeks & Subjects & Topics \\
\hline First & Anatomy & Bones \& muscles \\
\hline Second & Physiology & Outline of systems \\
\hline Third & Exercise Therapy & $\begin{array}{l}\text { Positioning, Exercises - Passive, Active, Resisted, Stretching, Breath- } \\
\text { ing exercises, Chest physiotherapy, Postural drainage, }\end{array}$ \\
\hline Fourth & Electrotherapy & Hot pack, Cryotherapy, Ultrasound, Infrared ray, TENS \\
\hline Fifth & $\begin{array}{l}\text { Physiotherapy in Ortho- } \\
\text { pedics Physiotherapy in } \\
\text { Cardio-Respiratory }\end{array}$ & $\begin{array}{l}\text { Degenerative conditions, Arthritis, Low back pain, Neck pain } \\
\text { Asthma, Bronchitis }\end{array}$ \\
\hline Sixth & $\begin{array}{l}\text { Physiotherapy in Neurol- } \\
\text { ogy Antenatal \& Postna- } \\
\text { tal classes }\end{array}$ & $\begin{array}{l}\text { Stroke, Spinal cord Injury, Parkinsonism, Guillian Barre Syndrome } \\
\text { Positioning, Breast feeding positions, Back care, Incontinence, Postu- } \\
\text { ral correction, Core muscle exercises, Diastasis Recti, }\end{array}$ \\
\hline
\end{tabular}

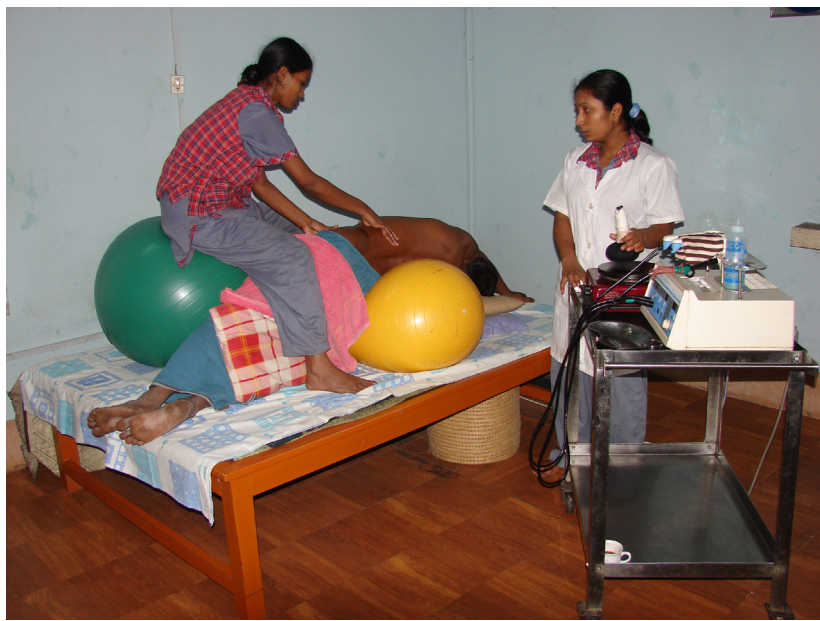

Figure 1. Paramedics treating with innovative techniques.

employment in rural areas as they hail from there. Including combination therapy into the community physiotherapy has brought more success has it can be easily applied in rural areas where there is lack of adequate space or electricity. For example instead of traditional hot packs, heat is applied with the help of portable stoves instead of electricity (Fig. 2).

Figure 3 and Table 3 show the difference in the number of patients between the urban (Dhaka) and rural centers (Savar, Sreepur and Vattshala) and also the common conditions for which people seek the help of a community physiotherapist. The difference in numbers is a result of the awareness and availability of physiotherapy services in urban areas compared to rural areas.

Degenerative conditions causing neck and back pain are common both in rural and urban areas. Patients visit a number of different health professionals before realizing that the correct treatment will be imparted by a physiotherapist. So by the time the patient reaches a physiotherapy department, $\mathrm{s} /$ he is already a victim of secondary complications. These patients respond well to a combined treatment approach.

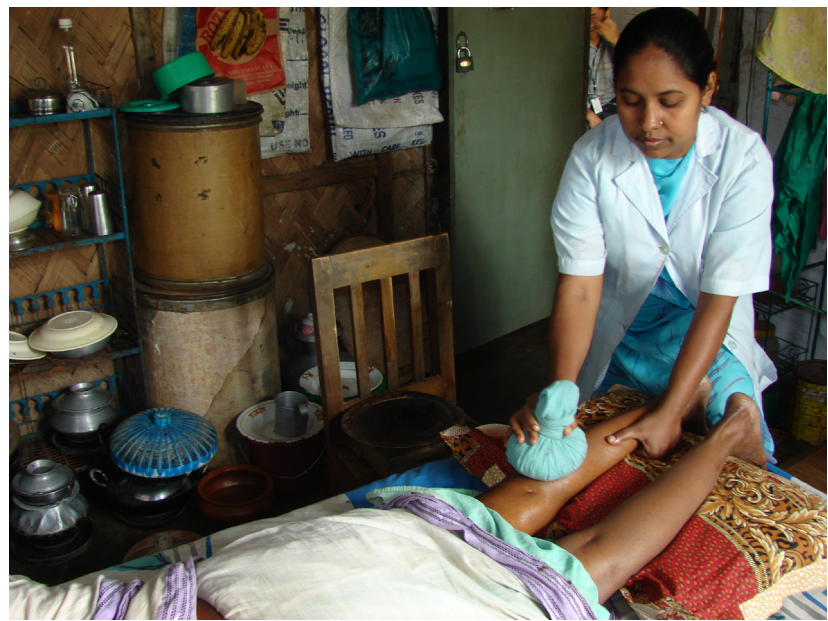

Figure 2. Community Based treatment - even without electricity.

\subsection{Health insurance policy}

Treatment at GK is not free. Each patient or family has to pay a monthly subscription, the amount determined by their socioeconomic status. People are charged for curative care only, not preventative health care. The aim is to change people's attitudes and encourage them to take more responsibility for preventing illness rather than relying on a cure when illness develops. The health insurance policy ensures equitable access to healthcare and the acceptance rate is also encouraging as shown in Table 4.

Based on the classification shown below in Table 5, GK's health insurance policy was designed mainly to target the poor, very poor and destitute.

\subsection{Behavioral training}

Behavioral training is essential which makes health workers smiling, energetic and extremely friendly with the patients. They must master the art of good communication and should be capable of transferring warmth to patients. 
Patient Demographic April 2002- April 2008

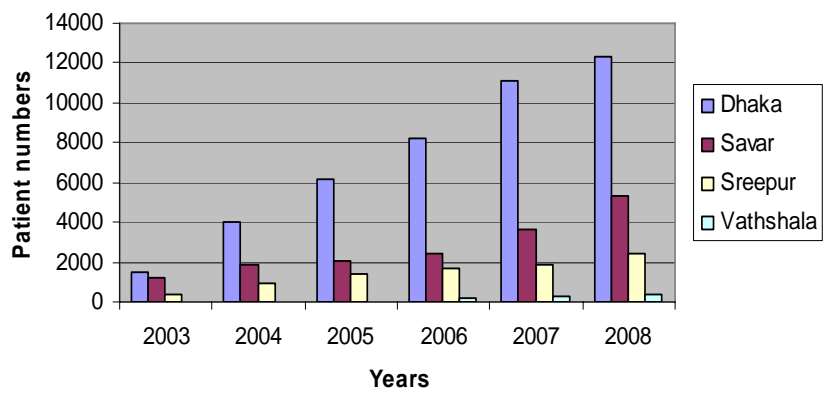

Figure 3. GK's Physiotherapy Patient demographic.

Table 3. Patient conditions April 2007-April 2008.

\begin{tabular}{clcccc}
\hline S.No & Conditions & Savar & Sreepur & Vattshala & Dhaka \\
\hline 1 & Back pain & 1976 & 645 & 167 & 3681 \\
2 & Knee pain & 823 & 489 & 67 & 1887 \\
3 & Neck pain & 481 & 267 & 31 & 1765 \\
4 & Shoulder pain & 512 & 213 & 12 & 1298 \\
5 & Ankle pain & 319 & 138 & 41 & 1172 \\
6 & Paralysis & 279 & 127 & 19 & 14 \\
7 & Wrist pain & 167 & 76 & 0 & 728 \\
8 & Cerebral Palsy & 143 & 42 & 9 & 9 \\
9 & Muscular pain & 203 & 121 & 22 & 612 \\
10 & Elbow pain & 43 & 56 & 0 & 427 \\
11 & Hip pain & 179 & 64 & 6 & 271 \\
12 & Burn & 83 & 11 & 0 & 117 \\
13 & Post fracture stiffness & 31 & 91 & 0 & 176 \\
14 & Respiratory problems & 73 & 49 & 0 & 205 \\
\hline & TOTAL & 5312 & 2389 & 374 & 12362 \\
\hline
\end{tabular}

\section{Results}

The main problem of physiotherapy as a profession in Bangladesh is the scarcity of well-qualified physiotherapists. GK has come a long way in overcoming this problem by educating and training more than 150 paramedics to fill the gap. Experienced paramedics are now able to administer treatment without direct supervision at all times, reducing the necessity of supervision. The number of patients seen by them is multiplying at a fascinating rate every year due to the growing recognition of their work.

Due to inter-professional conflicts and lack of cooperation and coordination, the referral system is non-existent between physicians and physiotherapists. Generally in Asian countries, if a patient has been advised physiotherapy treatment, $\mathrm{s} / \mathrm{he}$ may not pay heed to the advice especially if a physiotherapist gives it. On the other hand, if a physician recommends physiotherapy, the patient is likely to oblige. In addition, there is no government post for physiotherapists either in urban or in rural areas. Therefore, physiotherapists never have the opportunity to prove to other medical professionals and also to the general people what they are capable of. In some cases, due to lack of opportunity, some of them lost their confidence in treating patients and started to work as technicians under physicians. But in the past few years this attitude has changed due to the good will of our patients. They started to talk about their recovery and how they became more mobile especially without medicines. In the past, we use to get referrals from physicians when it involves either his/her family members or him/herself and now this has changed. Thus, the work of these paramedics has bought credibility to this profession and indirectly to the professionals.

According to the survey "Comparative advantages of public and private health care providers in Bangladesh" by World Bank, 2005 which states:

\begin{tabular}{lcc}
\hline Particulars & Poor (\%) & Very Poor (\%) \\
\hline $\begin{array}{l}\text { Government Health com- } \\
\text { plex \& Government doctor }\end{array}$ & 9 & 12 \\
$\begin{array}{l}\text { Government doctor work- } \\
\text { ing in Private clinic }\end{array}$ & 10 & 21 \\
Private clinic or Hospital & 24 & 24 \\
NGO service & 3 & 2 \\
Village doctor or Quacks & 10 & 8 \\
and others & 44 & 33 \\
$\begin{array}{l}\text { Local pharmacy or } \\
\text { medicine seller }\end{array}$ & 100 & 100 \\
\hline Total in \% & \\
\hline
\end{tabular}

The table pinpoints the accessibility of health care in Bangladesh in rural areas. The possible reasons for the people largely approaching the local pharmacist rather than the doctors is just to avoid the consultation fee or the absenteeism of doctors in rural areas (Chaudhury and Hammer, 2003) or the poor accessibility of health service. GK is trying hard to change this percentage by providing PHC at the doorsteps of the people by involving more trained and skilled paramedics.

Disabled and elderly people suffer, not only from medical problems but, also from lack of moral and psychological support due to loneliness. For these patients mental support is more important than the actual medical treatment. Community physiotherapists tend to spend more time with patients; using a more hands-on approach with patients instead of just handing out pills; their patience with the elderly and their reassuring words are more comforting and effective than any other treatment option. 
Table 4. GK's health insurance policy.

\begin{tabular}{|c|c|c|c|c|c|c|}
\hline Item wise service charge & Destitute & Ultra poor & Poor & Middleclass & Rich & $\begin{array}{l}\text { Without Health } \\
\text { Insurance }\end{array}$ \\
\hline Annual Premium/Smoker & 7.00 & 8.00 & 12.00 & 60.00 & 100.00 & NA \\
\hline Annual Premium/Non-smoker & 5.00 & 6.00 & 10.00 & 50.00 & 80.00 & NA \\
\hline Consultation with Medical officer/Paramedic & 2.00 & 3.00 & 5.00 & 8.00 & 12.00 & 15.00 \\
\hline \multirow{2}{*}{$\begin{array}{ll}\text { Consultation with senior doctor } & \text { 1st visit } \\
& \text { Subsequent Visit }\end{array}$} & Free & Free & 20.00 & 75.00 & 100.00 & 125.00 \\
\hline & Free & Free & 15.00 & 50.00 & 75.00 & 100.00 \\
\hline Medicine cost as $\%$ of MRP & Free & $50 \%$ & $75 \%$ & $100 \%$ & $100 \%$ & $100 \%$ \\
\hline EPI & Free & Free & Free & Free & Free & Free \\
\hline $\mathrm{ANC} \& \mathrm{PNC}$ & Free & Free & Free & Free & Free & Free \\
\hline Neonatal checkup & Free & Free & Free & Free & Free & Free \\
\hline Nutrition \& Sanitation Education & Free & Free & Free & Free & Free & Free \\
\hline Free Distribution of Vegetable Seeds and Seedlings & Free & Free & Free & $\begin{array}{l}\text { Price of seeds } \\
\text { and seedlings }\end{array}$ & $\begin{array}{l}\text { Price of seeds } \\
\text { and seedlings }\end{array}$ & $\begin{array}{l}\text { Price of seeds } \\
\text { and seedlings }\end{array}$ \\
\hline Temperature Check \& Nail Cutting & Free & Free & Free & 2.00 & 3.00 & 5.00 \\
\hline BP Check & Free & Free & Free & 3.00 & 5.00 & 6.00 \\
\hline Ear Wax removal & Free & Free & Free & 5.00 & 7.00 & 10.00 \\
\hline Dental Check & Free & Free & Free & 5.00 & 7.00 & 10.00 \\
\hline Lice Treatment with Benzoal Benzoate lotion & Free & Free & Free & 5.00 & 10.00 & 15.00 \\
\hline $\begin{array}{l}\text { Elderly Visit including nail cutting, } \\
\text { Temperature measure and BP check }\end{array}$ & Free & Free & Free & 5.00 & 7.00 & 10.00 \\
\hline Diabetic Check: Sugar in Urine & Free & Free & Free & 5.00 & 7.00 & 10.00 \\
\hline Community Physiotherapy (each visit) & Free & Free & 5.00 & 20.00 & 30.00 & 40.00 \\
\hline Acceptance of GK's Health Insurance & $100 \%$ & $100 \%$ & $78.9 \%$ & $22.8 \%$ & $3.36 \%$ & - \\
\hline
\end{tabular}

${ }^{*}$ MRP $=$ Maximum Retail Price with VAT as fixed by the GOVT

EPI = Extended Programme of Immunization

$\mathrm{ANC}=$ Ante Natal Care

PNC $=$ Post Natal Care

NA $=$ Not Applicable

1 Dollar $=69$ Taka

\section{Discussion}

The absolute annual growth of the disabled population in Bangladesh is approximately 250000 (Impact Foundation Bangladesh, 2002). There are approximately 6 times more people with disabilities in rural areas than in urban areas (Japan International Cooperation Agency Planning and Evaluation Department, 2002). However, medical and rehabilitation facilities are concentrated in urban areas. Rural persons with disabilities have no other alternative but to turn to traditional, often inappropriate or inadequate treatment. In order to improve services for rural persons with disabilities, it is necessary to establish an accessible health service, solve transportation problems and eliminate or subsidize facility usage fees. Fees have often prevented access to facilities. Thus GK believes in non-institution based rehabilitation by promoting community physiotherapy. Currently GK is providing community physiotherapy services at four centres and in the other seven sub-centers the paramedics act as referrals. GK also has the credit of opening an Obstetric physiotherapy centre (Fig. 4) and home service for the first time in Bangladesh (Fig. 5). In the near future, GK has plans to extend this innovative service to all other sub-centers.

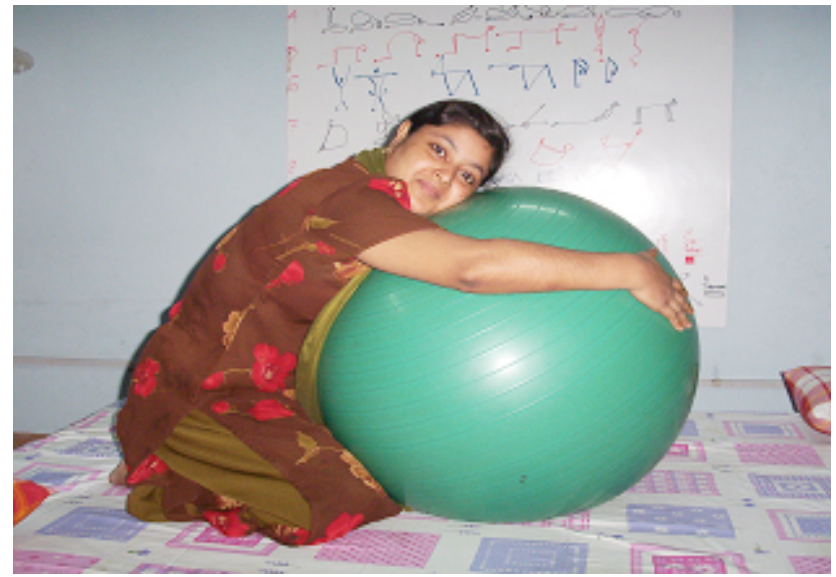

Figure 4. Antenatal care for pregnant women.

Paramedic's education and training should be a continuous process. Their training needs in terms of technical, managerial and behavioral aspects should be identified (Ray, 2001). Every six months, the trained paramedics are brought to the main centre to encourage them to share their experiences 
Table 5. GK's Project wise family chart.

\begin{tabular}{lcccccc}
\hline \multirow{2}{*}{ Name of the } & \multicolumn{5}{c}{ Families } \\
\cline { 2 - 7 } Sub center & Destitute & Ultra poor & Poor & Middle class & Rich & Total family \\
\hline Pathalia & 6 & 14 & 3659 & 5440 & 640 & 9759 \\
Dham sona & 12 & 29 & 3596 & 12041 & 641 & 16319 \\
Zoron & 7 & 37 & 4238 & 7263 & 894 & 12439 \\
Panishal & 8 & 47 & 3887 & 3295 & 403 & 7640 \\
Shimulia & 36 & 154 & 5485 & 4189 & 437 & 10301 \\
Baro baria & 17 & 51 & 5498 & 2134 & 373 & 8073 \\
Saturia & 21 & 23 & 6390 & 4504 & 443 & 11381 \\
Sreepur & 92 & 362 & 14558 & 7077 & 1289 & 23378 \\
Vatshala & 88 & 417 & 16916 & 3388 & 448 & 21257 \\
Sona gazi & 31 & 62 & 5123 & 2256 & 329 & 7801 \\
Shivganj & 13 & 117 & 12894 & 4189 & 1497 & 18710 \\
Char Fashion & 52 & 924 & 9646 & 1478 & 385 & 12485 \\
Cox Bazaar & 198 & 479 & 13157 & 1576 & 502 & 15912 \\
Kashinathpur & 43 & 155 & 10941 & 3232 & 805 & 15176 \\
Sirajganj & 217 & 521 & 16175 & 3118 & 469 & 20500 \\
Parbatipur & 74 & 164 & 5001 & 1317 & 742 & 7298 \\
Kancipur & 163 & 1059 & 3768 & 832 & 160 & 5982 \\
Delduar & 2 & 55 & 4188 & 1645 & 159 & 6049 \\
\hline Total & 1080 & 4670 & 145120 & 68974 & 10616 & 230460 \\
\% & 0.47 & 2.03 & 62.97 & 29.93 & 4.61 & \\
\hline
\end{tabular}

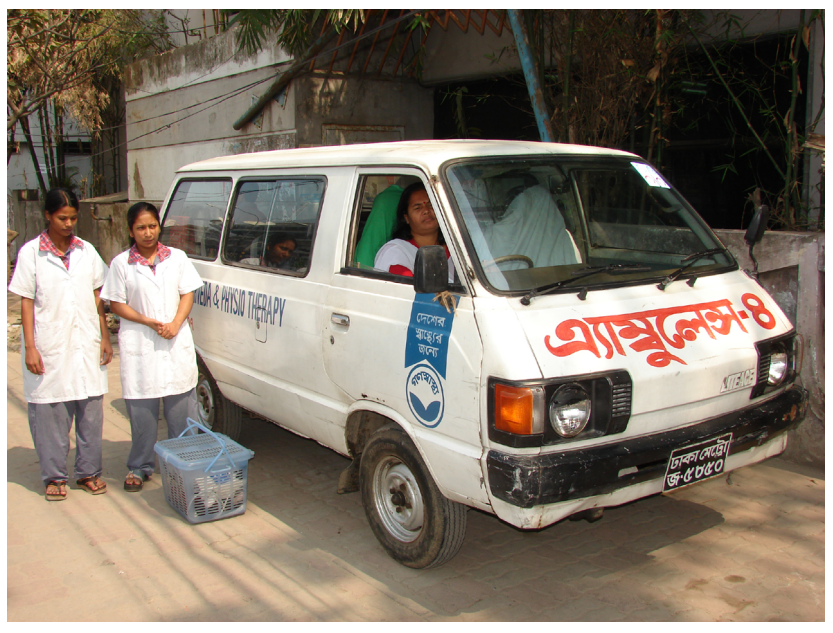

Figure 5. Home visit through Mobile Physiotherapy Unit.

while treating patients and give feedback on how to improve performance. Whenever our physiotherapist or internee students make a visit to the subcentres, they accompany the paramedics to the field and sometime they also take classes during their field visit (Fig. 6). In the future we are planning to conduct this feedback session every three months which will then further help to boost their confidence while handling patients.

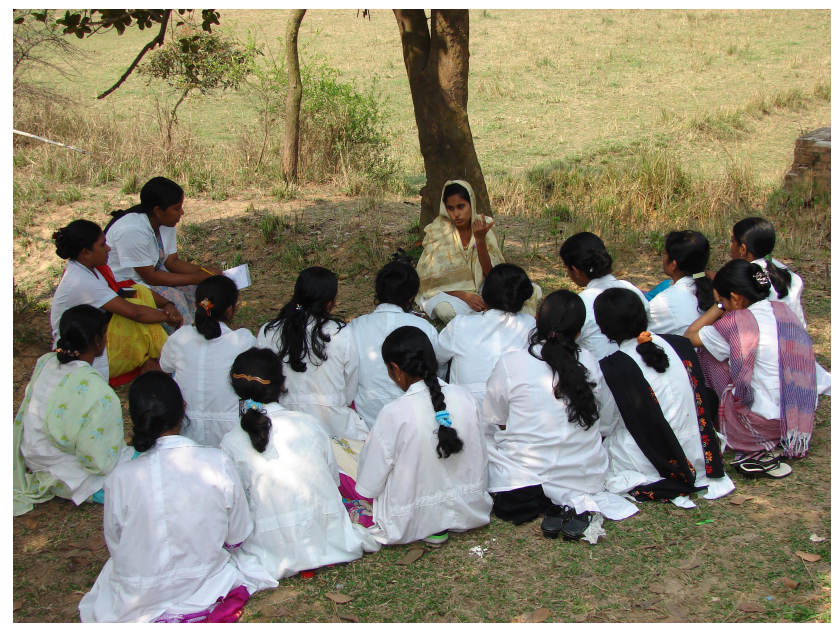

Figure 6. Paramedics training in field.

When the training program was started, there were questions raised about the quality of these paramedics and in some cases the paramedics were considered as mere competitors by the physiotherapist themselves. But soon they realized that by working in remote villages, where professionals themselves never dreamt of going, paramedics created awareness that there exists a profession which can prevent and cure ailments without use of medicines. Students 
enrolled in the BSc program in physiotherapy at Gono Bishwabidyalay are also involved in paramedics training. They take basic anatomy and physiology classes which enables an establishment of good relationships between the paramedics and the future physiotherapists. GK is the sponsor of Gono Bishwabidyalay (People's University), started in 1998, the only institution which has both Health and Social faculties and which tries to promote an integrative approach through its training programs. GK will continue to work towards creating an environment where paramedics and physiotherapists can work together along with other rehabilitation workers for improving the health care for rural patients.

The purpose of this article has been to draw the attention of WHO and other international oranizations to the existing situation of physiotherapy in developing countries in general and Bangladesh in particular. Along with this, we have attempted to highlight the innovations in community physiotherapy in enhancing easy and equitable access. When the paramedics visit the homes of patients who don't have their own son or daughter or grand children around them, they endear themselves to the elderly. A touch provides a powerful comfort that is better than a thousand pain killers.

\section{References}

Bose, A.: Women's Empowerment thtough capacity building - Enduring efforts in Bangladesh, 2004.

Canadian Alliance of Physiotherapy Regulators \& the Canadian Physiotherapy Association: Physiotherapy Health Human Resources, Background paper, 2002.

Chaudhury, N. and Hammer, J.: Ghost doctors: absenteeism in Bangladeshi health facilities, Policy Research Working Paper No. 3065, Washington, D.C., The World Bank, 2003.

Chowdhury, S. and Chowdhury, Z.: Tubectomy by Paraprofessional Surgeons in Rural Bangladesh, Lancet, 2(7935), 567-569, 1975.

Editorial, Gonoshasthaya Kendra, The Lancet, 1(7949), 26-27, 1976.

Gonoshasthaya Kendra: Evaluation Report, Gonoshasthaya Kendra, Savar, 2008.

Haque, T.: With The People, For The People, Gonoshasthaya Kendra, Bangladesh, The People's Health Centre, 2003.

Impact Foundation Bangladesh, Disability statistics, 2002.

Japan International Cooperation Agency Planning and Evaluation Department, Country Profile on Disability, People's Republic of Bangladesh, 2002.

National Health Policy - An Update, Ministry of Health and Family Welfare Government of the People's Republic of Bangladesh, http://www.mohfw.gov.bd/New_Folder/Health\% 20Policy_english.pdf, August 2008.

Ray, B.: Human Resource Planning in Health Care, Tata Main Hospital, Jamshedpur India, Health Administrator, 11-13(1-2), 146, Jul-Dec 2001.

The World Bank Office, Dhaka: To the MDG's and Beyond: Accountability and Institutional Innovation in Bangladesh, Bangladesh Development Series Paper No. 14, 2007.

World Health Organization (WHO): The World Health Report, Health workers: a global profile, Chapter 1, 2006. 